\title{
Comparative Experimental Evaluation of Dust Sensors for Environmental Monitoring on Construction Sites
}

\author{
A. Carbonari ${ }^{a}$, G. Fava ${ }^{\mathrm{b}}$ and B. Naticchia ${ }^{\mathrm{b}}$ \\ ${ }^{a}$ Department of Civil, Building Engineering and Architecture, Polytechnic University of Marche, Ancona, Italy \\ ${ }^{b}$ Department of Materials, Environmental Sciences and Urban Planning, Polytechnic University of Marche, Ancona, \\ Italy \\ E-mail: alessandro.carbonari@univpm.it,g.fava@univpm.it, b.naticchia@univpm.it
}

\begin{abstract}
-
Fine particle emissions $\left(\mathrm{PM}_{10}\right)$ from demolition and construction activities are now recognized as significant causes of pollution. So they can cause health hazards both to workers and to people living and working outside the site's boundary in the local neighbourhood. Although admissible concentration values are defined by national legislation and regulations worldwide, there is no permanent monitoring system in place, yet. Hence, in this paper one step pertaining to the development of a wireless pervasive and real-time monitoring system of dust concentration will be presented. In particular, it will focus on the types of sensors, integrated in the communication network, which can be used to the purpose. In particular, we will compare the performances of two different dust sensors. On principle, they are all suitable for wireless monitoring, but not all the sensors have the same sensitivity to changeable particles diameter sizes and types of dust. So a dedicated laboratory campaign was carried out, in order to compare their performances with the ones of a reference instrument (used as a benchmark). The comparisons show that there is a good agreement between the plots of the wireless real-time tracking system and the benchmark. However, the reliability of the sensors to detect events (e.g. sudden dust concentration variation) and particles with nonuniform particle distribution is different according to the kind of dust sensor which is integrated in the wireless system.
\end{abstract}

Keywords -

Dust tracking; wireless sensor network; health and safety.

\section{Introduction}

Monitoring fine particle emissions $\left(\mathrm{PM}_{10}\right)$ is needed to face one of the main causes of pollution and health problems [1]. Workers in construction sites and people living in the local neighbourhood can be strongly affected by emissions from demolition and construction activities. Then, that fine dust can easily be carried in the air and penetrate further in the airways, causing well recognized health-problems.

In the construction field, $\mathrm{PM}_{10}$ is originated by several concurrent factors, determined on one hand by site layout and organisation and, on the other, by the type of demolition or construction activities in progress. Dust and mud from roads and haulage routes on the site can become airborne through the movement of vehicles. Vehicles and some plants also generate engine exhaust emissions. In addition, the handling and storage of fine, powdery and dry materials has the potential for making the dust airborne. Additional contributions to dust generation comes from a number of fabrication processes, among which we cite cutting, grinding, sandblasting, drilling and disk cutting.

The legislation relating to health and the environment mostly defines admissible ambient dust concentration as a running 24-hour mean, e.g. both the World Health Organisation [2] and the UK Air Quality Strategy, under Part IV of the Environmental Act [3], define a target average $\mathrm{PM}_{10}$ value equal to $50 \mu \mathrm{g} / \mathrm{m}^{3}$.

In the USA, the Clean Air Amendment dated 1990 incorporated into Title 42, Chapter 85 of the United States Code - regulates emissions from any facility into the air. The National Ambient Air Quality Standards (NAAQS) specify dust admissible in the outdoor air as a twenty-four hour average $\mathrm{PM}_{10}$. It must not exceed 150 $\mu \mathrm{g} / \mathrm{m}^{3}$, whereas its annual average must not exceed $50 \mu \mathrm{g} / \mathrm{m}^{3}$ [4]. Such legislation is also present in other countries: e.g. ambient air quality in Italy is ruled by Legislative Decree no. 152/2006. Annex V of this decree concerns outdoor air quality and limitation of outdoor air inclusions. It states that control measures of dust levels in outdoor air must be put in place any time dust generating activities are undergoing. The nature of such control activities shall be adequate to the hazards determined by the type and amount of dust, weather conditions and protection needed by the surroundings. So there is no pre-determined limit, whose assessment is, in fact, in charge of the person leading the dust 
generating tasks. Anyway, even in Italy the reference level of outdoor air quality is usually taken as the value suggested by WHO.

On the other hand, regulations relating to occupational exposure define limit values in terms of an $8 \mathrm{hr}$ Time Weighted Average (TWA) of total inhalable dust, whose thresholds differ slightly depending on the country.

Recommended control measures are those which reduce dust generated at its source [1]. Pre-project risk assessment is able to identify risks and mitigation actions, but cannot quantify their real effectiveness, which is strongly dependent on operational approaches, unless monitoring techniques are used. So far two main monitoring methods have been employed, according to relevant regulations [5]:

- pumped samplers that collect particles on a filter for later weighing or chemical analyses (generally held on site for some days or weeks), which is known as the gravimetric approach;

- continuous sampling instruments to provide fast online plots of dust concentration (e.g. light scattering), thanks to the use of optical instruments.

The work presented in our paper has the purpose of contributing to the second approach, by means of an advanced and non-invasive wireless sensor network, which is able to provide pervasive and continuous monitoring of the presence of dust on site. This new system was conceived so as to complement current monitoring techniques, by means of a platform which can be kept continuously on throughout the whole construction process.

In fact, the presence of this sensor set, capable of tracking dust concentration in real-time, is critical for obtaining a reliable picture of spatial dust distribution. Thus, once cheap, easy to deploy and pervasive sensor networks are available, they should determine several benefits, such as:

- triggering of warnings, when dust values exceed pre-determined thresholds;

- $\quad$ reduction in the number of environmental offences and hence in prosecutions by local authorities, which is a relevant financial burden for builders [6]; - reduction in the site engineer's workload;

- reduction in the health damage to the workers.

In Section 2 a description of the pervasive network is presented. Section 3 will report on laboratory calibration of the sensors and Section 4 will describe on fieldexperiments. Finally Section 5 will report our Conclusions.

\section{Pervasive dust monitoring platform}

This paper suggests setting up a real-time monitoring system which is capable of crosschecking the position of workers and the estimated dust concentrations over the site. Such a system would provide at least a couple of significant services in construction sites:

- capability of signaling in real-time the overcoming of any predetermined threshold values;

- gradual implementation of a database containing the cumulative value of the amount of PM concentration to which workers have been exposed, integrated over several possible meaningful time windows.

In the schematic shown in Fig. 1, every worker is supposed to be tracked using one of the available position tracking systems developed for construction sites; then the new sensors described in this paper are deployed over the site and programmed so as to give back in real time the dust concentration values at their known positions (in order to work like that, even they need to be equipped with a wireless tag device for being automatically located).

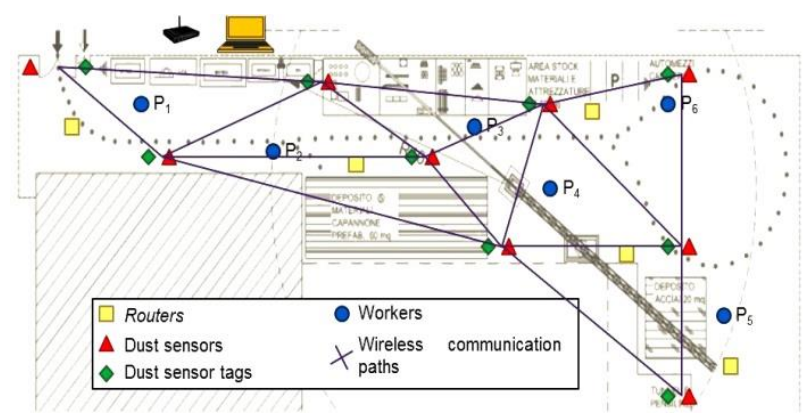

Fig. 1 - Schematic of the monitoring system logics.

So a preliminary network prototype to monitor the concentration of particulate matter - $\mathrm{PM}_{10}$ - was developed and tested in the machine laboratory of the DICEA Department and of the SIMAU Department at Università Politecnica delle Marche (Ancona, Italy).

\subsection{The communication platform}

The wireless communication network is based on the SmartNetwork Platform, an ultra-low power wireless technology (manufactured by Smart Space Solutions srl). It is capable of tracking large areas with a wireless mesh network architecture, made up of battery operated devices. The SmartNetwork includes three levels of devices: one or more coordinators, routers and sensors.

Routers forward messages across the network devices, they support complex, self-configuring and self-healing mesh networks with as many as 65,000 nodes. Routers provide network area coverage, they dynamically route around obstacles, and provide backup routes in case of network congestion or device failure.

Interaction among the three levels of devices makes the overall communication possible (Fig. 2). One or more PAN coordinators are used to initiate network 
formation; routers are responsible for performing multihop routing of messages; end devices (also called "reduced function devices-RFD") act as multi-purpose sensors and do not have routing capabilities.

The hallmark of SmartNetwork components is that they use a special hardware and firmware architecture capable of sensing an RF wakeup impulse with extremely low power consumption (as low as $0.05 \mathrm{~mW}$ ), hence they can be battery powered. Once the appropriate nodes of the network are awakened, the transmission is performed through the network using the primary radio system which returns to sleep mode when no data need to be transferred. This technology allows a long time-span between two consecutive battery replacements, usually in the order of a few years [7].

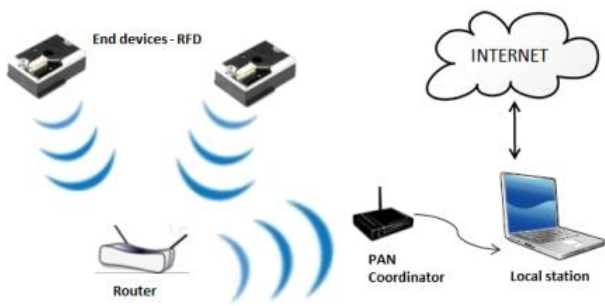

Fig. 2. Layered architecture of the wireless communication network used for dust tracking.

\subsection{Types of sensors which were compared during our trials}

Our market survey gave back two main manufacturers of dust sensors: Shinyei and Sharp. Both products are based on the same operation principle: a light beam is emitted into a measurement chamber; when dust is present, the light is refracted by particles and the amount of scattered light is detected. One unique feature of the first set of sensors is that Shinyei ones use a heating resistor to create an updraft, hence it is active. On the other hand, the Sharp GP2Y1010 optical dust sensor is mostly used in air quality equipment, such as air purifiers, it has no embedded heater and it works as a passive dust sampler.

\subsubsection{The active dust sampler}

The active dust sampler was embedded in a package split into two chambers (Fig.3-a). The left sided chamber including a micro-processor for processing data and sending them to the communication system, besides a lithium battery, made necessary because of the presence of a heather. The heather was placed at the bottom of the right sided chamber along with the probe, because after air was made flow upwards, the probe could collect records of dust concentration.

Technically, this sensor creates a Digital Lo Pulse output, whose pulse occupancy time is in proportion to
PM concentration (Tab. 1). When dust is not present, then the Hi Pulse output is given as a results (Fig. 3-b). It means that the Lo Pulse occupancy time it detects is expressed as a percentage over the total measurement time window. Hence, every record is the result of the measurements carried out over that time span. Considering that the time for stabilization required by such sensor is about $60 \mathrm{~s}$ after power is turned on, we programmed it so that $60 \mathrm{~s}$ were used for stabilization and $30 \mathrm{~s}$ for measuring. Time for stabilization is due mainly to the presence of the heater, which is expected to trigger an upward air flow. As a consequence, one record every $90 \mathrm{~s}$ was provided by this senor.

Tab. 1 Main parameters of the Shinyei PPD42NJ dust sensor.

\begin{tabular}{llc}
\hline \multicolumn{1}{c}{ Parameter } & Units & $\begin{array}{c}\text { Typical } \\
\text { Value }\end{array}$ \\
\hline Supply Voltage & $\mathrm{V}$ & DC 5V \\
Operating Temperature & ${ }^{\circ} \mathrm{C}$ & $0-+45$ \\
Hi Pulse Voltage (no & $\mathrm{V}$ & $>4.5$ \\
dust) & $\mathrm{V}$ & $<0.7$ \\
Lo Pulse Voltage & $\mathrm{mA}$ & 90 \\
Consumption current & &
\end{tabular}

(a)

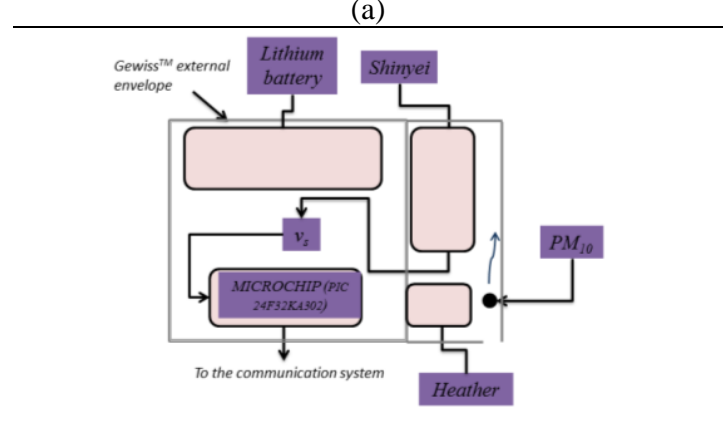

(b)

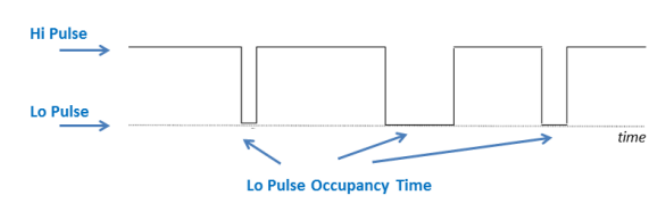

Fig. 3. Schematics of the active sensor's components (a) and conceptual measurement approach based on Lo pulse occupancy time (b).

\subsubsection{The passive dust sampler}

The Sharp dust sensor (Tab. 2) is equipped with a hole in the middle (i.e. measurement chamber), across which air is free to flow and dust concentration is measured by means of the light scattering principle (Fig. $4)$. 
Tab. 2 Main parameters of the Sharp GP2Y101AU0F dust sensor.

\begin{tabular}{llc}
\hline \multicolumn{1}{c}{ Parameter } & Units & $\begin{array}{c}\text { Typical } \\
\text { Value }\end{array}$ \\
\hline Supply Voltage & $\mathrm{V}$ & $-0.3-+7$ \\
Operating Temperature & ${ }^{\circ} \mathrm{C}$ & $-10-+65$ \\
Sensitivity & $\mathrm{V} /\left(0.1 \mathrm{mg} / \mathrm{m}^{3}\right)$ & 0.5 \\
$\begin{array}{l}\text { Output voltage at no } \\
\text { dust }\end{array}$ & $\mathrm{V}$ & 0.9 \\
Consumption current & $\mathrm{mA}$ & 11 \\
\hline
\end{tabular}

Technically, the Sharp dust sensor's measurement chamber causes a pulse whose voltage is proportional to the number of particles which caused the light beam to be diffracted $\left(\mathrm{V}_{\mathrm{s}, \mathrm{i}}\right)$ [8]. The microprocessor works out the mean $\left(\mathrm{V}_{\mathrm{s}}\right)$ based on the last 16 records. The time step at which pulses were generated was set equals to 10 $\mathrm{s}$, determining about 6 records per minutes.

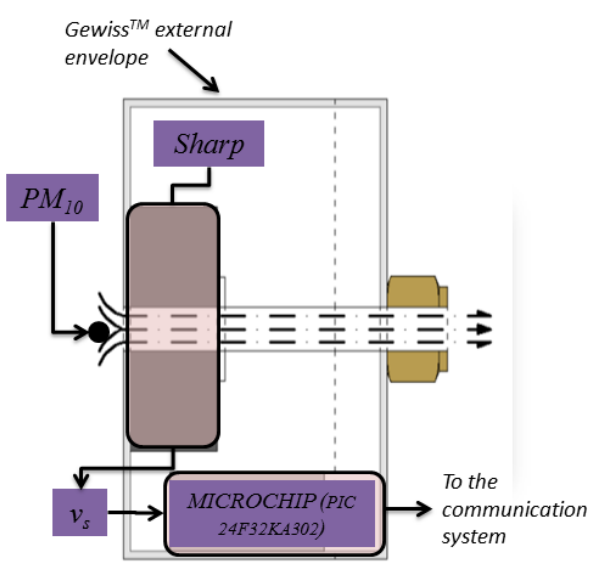

Fig. 4. Schematics of the passive sensor's components.

\section{Laboratory tests}

Laboratory tests under controlled conditions were performed to calibrate the two types of sensors described above. Both were calibrated against the measurements of a highly accurate sensor, which was used as a benchmark.

\subsection{Measurement setup}

The two sensors' characterisation and calibration was performed in the concrete laboratory of the Simau Department at the Università Politecnica delle Marche, under controlled conditions in order to avoid bias by unknown factors. A dust ventilation duct was setup in order to place the sensors and control the physical variables during testing (Fig. 5). The duct was made of a $10 \mathrm{~m}$ long by $0.7 \mathrm{~m}$ wide by $0.7 \mathrm{~m}$ high insulated aluminium coated casing (AC), connected to a vertical substructure (VS) with a grid (at the intersection between the two) for homogenising the inlet generation.
Sea salt dust generation (DG) was provided by means of an ultrasonic fog generator placed at the inlet of the dust ventilation duct.

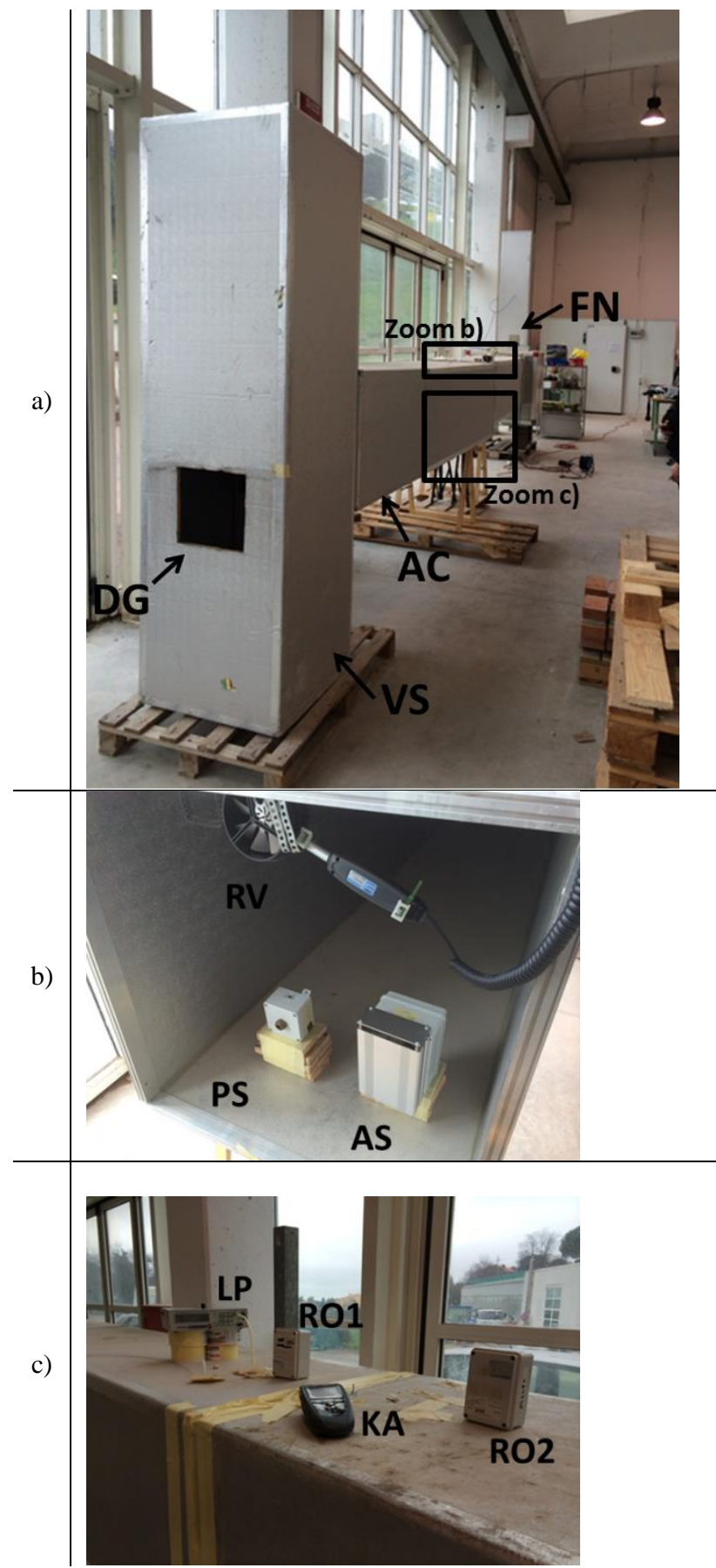

Fig. 5 - Deployment of the measuring setup inside and outside the ventilation duct (a); zoomed view of the instruments placed on the duct (b) and in the measurements cross section (c).

The ultrasonic fog generator uses ultrasonic technology to produce a fog composed of $10 \mu \mathrm{m}$ and less 
sized water particles which gives smaller solid particle diameter as determined by eqs. (1) and (1) [9]:

$$
\begin{aligned}
& D_{g}=0.34 \cdot\left(\frac{8 \pi T_{w}}{d_{w} \cdot f^{2}}\right)^{\frac{1}{3}} \\
& D_{p}=D_{g} \cdot\left(\frac{C_{w}}{d s} \cdot 10^{6}\right)^{\frac{1}{3}}
\end{aligned}
$$

where $D_{g}$ is the fog drop diameter, $D_{p}$ is the solid particle diameter, $d_{w}$ is water density, $T_{w}$ is surface tension $\left(\right.$ dine $\left./ \mathrm{cm}^{2}\right), \mathrm{f}$ is the ultrasonic frequency $(\mathrm{MHz})$, $\mathrm{C}_{\mathrm{w}}$ the solute concentration $(\mathrm{g} / \mathrm{L})$ and $\mathrm{d}_{\mathrm{s}}$ the solute density $(\mathrm{g} / \mathrm{L})$.

A filter along the duct guaranteed diffusion of the generated dust. At one end of the duct a fan $(\mathrm{FN})$ was used to generate controlled and uniform air flow along the duct. The passive sensors (PS) and the active sensor (AS) were placed downstream inside the duct aside the benchmark (Grimm) laser photometer (LP). The passive and active sensors sent data to a couple of routers (RO1 and $\mathrm{RO} 2$ ) located on the top outer surface of the ventilation duct. These routers forwarded data from both sensors to one coordinator inside the laboratory, connected to a laptop at a short distance from the duct.

The benchmark instrument measured $\mathrm{PM}_{10}$ through an active technique. It used an optical particle counter Grimm 1.108, which is a portable laser photometer (LP) with a constant volume flow of 0.6 1/min and a digital display for real-time measurement. Finally, a removable $47 \mathrm{~mm}$ PTFE filter was incorporated inside the instrument in order to collect all the measured dust, so that, at any later time, an appropriate density verification/correction would be possible. This filter is in accordance with many national and ISO standards. The air flow rate inside the dust ventilation duct was generated by the rotating fan $(\mathrm{FN})$ and its amount estimated by means of a multi-probe thermo-anemometer VT200 manufactured by Kimo Instruments (KA), equipped with a rotating vane anemometer with diameter $100 \mathrm{~mm}$ (RV), whose measurement range spans from 0.25 to $3 \mathrm{~m} / \mathrm{s}$ and whose accuracy is $3 \%$ on the measurement and maximum accuracy $0.01 \mathrm{~m} / \mathrm{s}$. The passive and active dust sensors and the Grimm sampler were all placed on the same section of the duct, thus making them suction air at the same point along its path.

During the trial the dust generator (generating dust with diameter between 0.23 and $10 \mu \mathrm{m}$ ) was kept on at a constant rate for almost two hours: from 12:00 pm until 1:53 pm, while the fan's rate was varied during the same time interval. The air speed was varied from the top speed $1.70 \mathrm{~m} / \mathrm{s}$ down to the slowest value of 0.60 $\mathrm{m} / \mathrm{s}$ and then increased again, as shown in Tab. 3. In this way the measurement capabilities of the two sensors were given as a function of external disturbances, e.g. wind when measurements take place either outdoors or in ventilated rooms.
Tab. 3 Speed of air flowing in the duct during the laboratory trial.

\begin{tabular}{ccc}
\hline $\begin{array}{c}\text { Air speed } \\
(\mathrm{m} / \mathrm{s})\end{array}$ & $\begin{array}{c}\text { Start time } \\
(\mathrm{hh}: \mathrm{mm})\end{array}$ & $\begin{array}{c}\text { End time } \\
(\mathrm{hh}: \mathrm{mm})\end{array}$ \\
\hline 1.70 & $12: 00$ & $12: 15$ \\
1.00 & $12: 15$ & $12: 34$ \\
0.60 & $12: 34$ & $1: 10$ \\
1.00 & $1: 10$ & $1: 33$ \\
1.70 & $1: 33$ & $1: 53$ \\
\hline
\end{tabular}

\subsection{Tests and discussion on the results}

The benchmark recorded one measurement every minute, while the Sharp and Shinyei samplers worked differently. The Sharp sensors recorded one measurement every $10 \mathrm{~s}$. Subsequently, post-processing worked out the average values per minute. The Shinyei sensor recorded one sample every 90 seconds, hence those data were resampled with a Matlab ${ }^{\mathrm{TM}}$ function to work out a one minute step database, when necessary. Thus, measurements from the three sensors where given the same time scale on the $\mathrm{x}$-axis and the results are pictured in Fig. 6, each sensor keeping its own units.

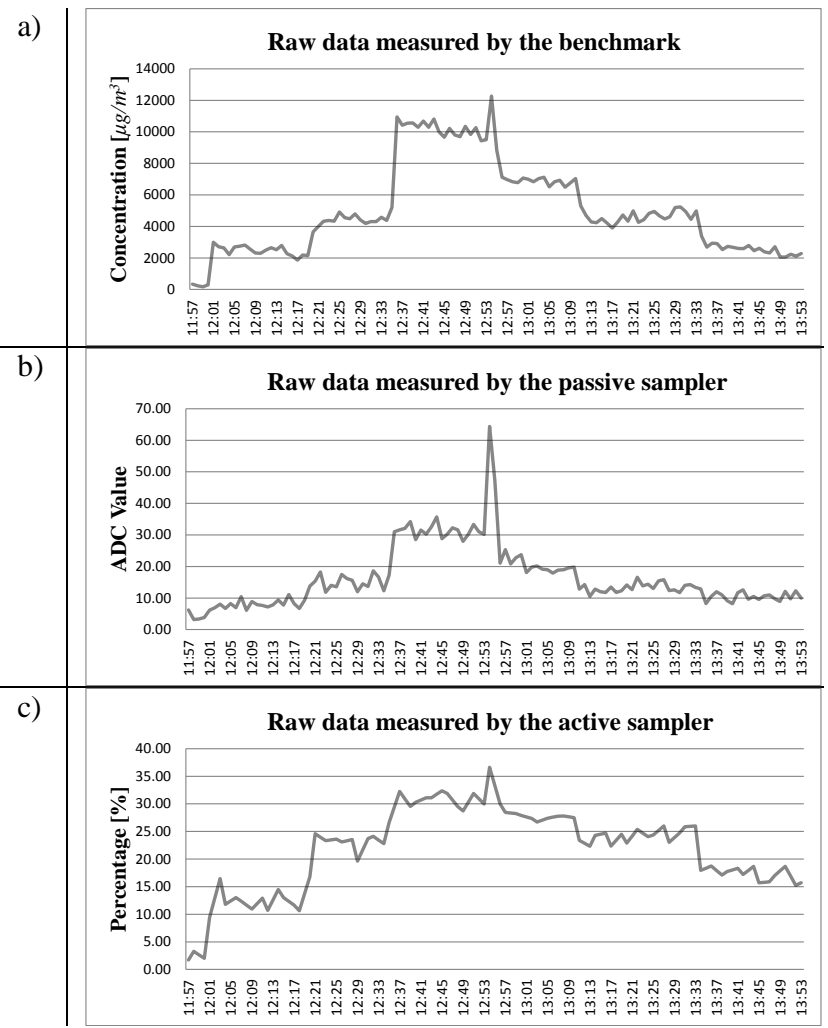

Fig. 6 - Measurements recorded by the benchmark (a), the passive (i.e. Sharp) sampler (b) and the active (i.e. Shinyei) sampler (c). 
This figure clearly shows that a qualitative agreement among the three sensors was had. As already stated in sub-section 3.1, the varying concentration sensed by the sensors was due to the variation of the air speed flowing across the ventilation duct.

Although the sensitivity of the benchmark is better than the sensitivity of the other two sensors, all of them follow similar trends. But a more accurate comparison followed from the estimation of conversion factors between the two experimental dust samplers and the benchmark. The need for these factors arise from the different units that each of the sensors give as outputs. They were worked out as the ratio between the average dust concentration measured by the benchmark during the tests and the average value sensed by the passive sensors over the same time lag.

Tab. 4 Conversion factors $(\mathrm{CF})$

\begin{tabular}{|c|c|c|}
\hline $\begin{array}{c}\text { Wind speed } \\
(\mathrm{m} / \mathrm{s})\end{array}$ & $\begin{array}{c}\text { Passive sampler } \\
\text { CF }\end{array}$ & $\begin{array}{c}\text { Active sampler } \\
\text { CF }\end{array}$ \\
\hline 0.60 & 314.4 & 291.1 \\
\hline 1.00 & 320.2 & 192.0 \\
\hline 1.70 & 276.2 & 169.2 \\
\hline
\end{tabular}

a)

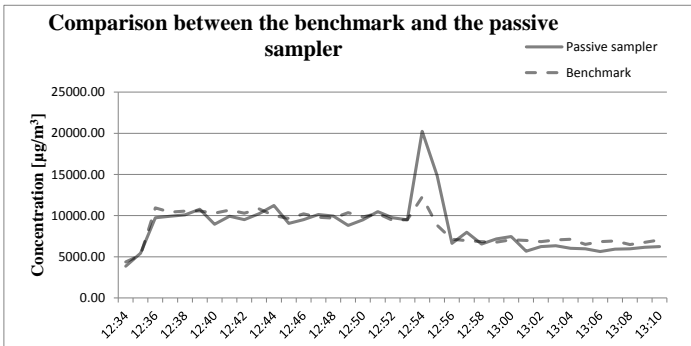

b)

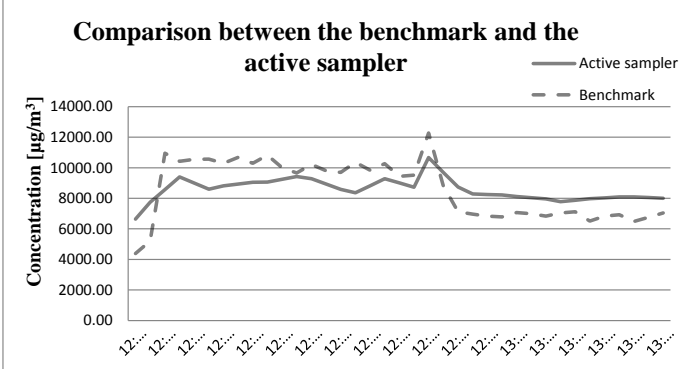

Fig. 7 - Comparison between the benchmark and the estimation provided by the passive (a) and active samplers (b).

Three conversion factors per each sensor were worked out, according to air speed across the ventilation duct. In other words, once wind speed are tracked and conversion factors are known, a monitoring system embedding these sensors should be able to provide a real-time rough estimation of $\mathrm{PM}_{10}$ concentration in construction sites. Tab. 4 summarizes those factors for the combination of cases under consideration. To be noticed that the correction factors of both sensors follow different trends, in that the active sensor's factors are lower at high air speed and higher at low air speed; on the contrary, not a similar trend is found in the case of the passive sensors. Comparing the two experimental sensors, the correction factors of the active sensor are always lower than the correction factors of the passive sensor. This suggests that the active sensor is more sensitive than the passive one, under controlled conditions.

a)

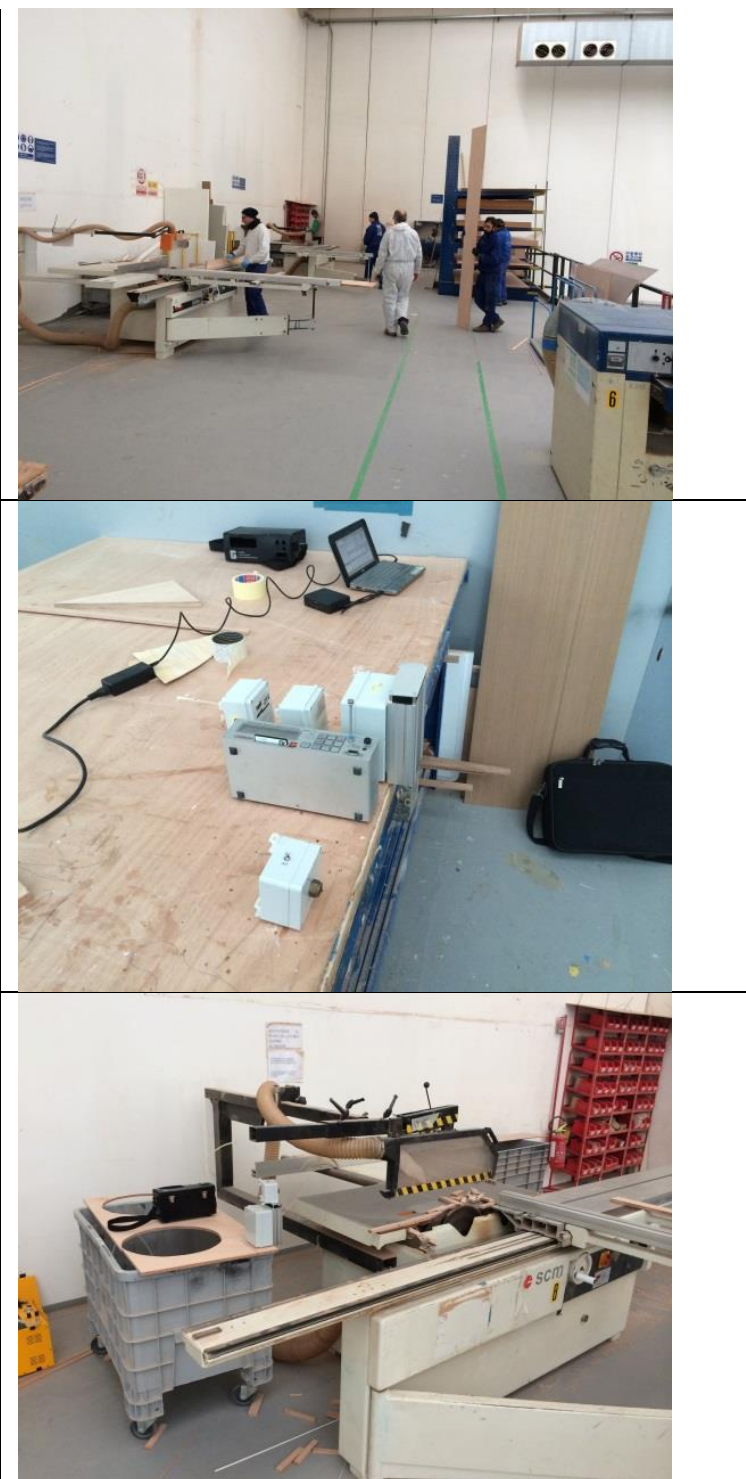

Fig. 8 - The wood cutting machine generating dust (a); view of the sensor position in the first trial (b) and in the second trial (c).

Fig. 7 shows what happens when the measurements recorded by the samplers at $0.60 \mathrm{~m} / \mathrm{s}$ are multiplied by each $\mathrm{CF}$, so that a direct comparison between the benchmark and the estimations provided by the 
samplers can be provided. The passive sampler overestimated the intensity of the peak, but was quite accurate outside this peak's window. The active sensor estimated better that peak but its deviations from the benchmark is bigger out of the peak's window. Anyway, both sensors performed quite well over the whole controlled conditions tests.

\section{Additional on-field experiments}

A real-world scenario was offered by a company running a ship yard located in the county of Ancona (Italy).

\subsection{Trials}

The first trial started at 9:10 am and run until 10:20 am. The same benchmark instrument described in subsection 3.1 was placed far from the machine but in the same room, and the two passive and active sensors were placed close by, as depicted in Fig. 8-b. The measurements collected during this time window were resampled with a 1 min wide step, same as what done with the laboratory experiments, so as to be able to compare both prototypical sensors with the benchmark, as shown in Fig. 9.

a)

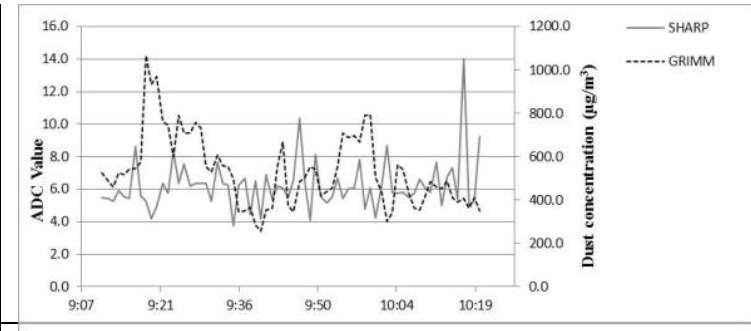

b)

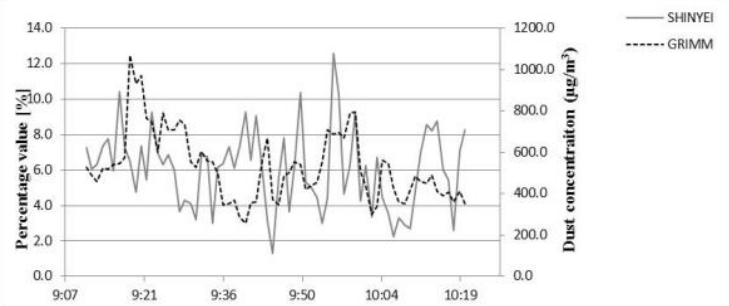

Fig. 9 - Comparison between the benchmark and the estimation provided by the passive (a) and active (b) dust samplers in the first on-field trial.

The second trial started at 12:30 pm and run until 1:30 pm. All the three sensors were placed besides the wood cutting machine, at the same height of the working desk, as shown in Fig. 8-c. Again, the measurements collected during this time window were resampled with a $1 \mathrm{~min}$ wide step, so as to be able to compare both prototypical sensors with the benchmark, as shown in Fig. 10.

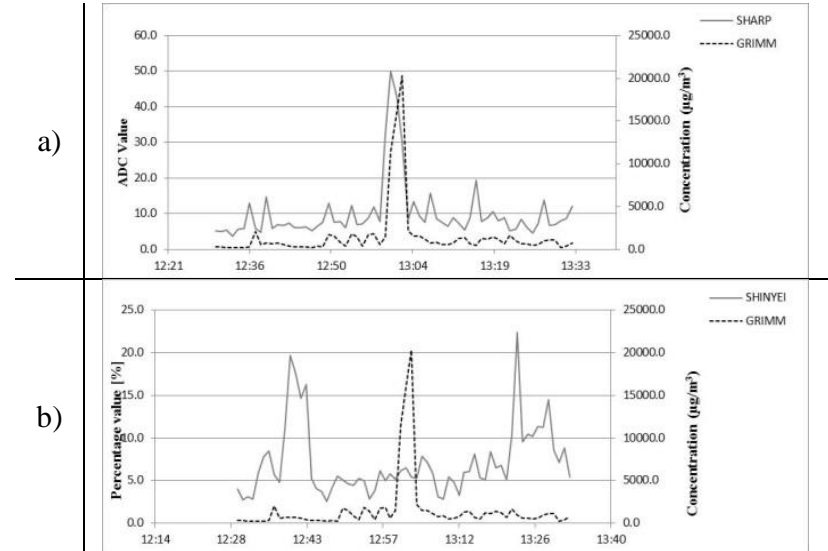

Fig. 10 - Comparison between the benchmark and the estimation provided by the passive (a) and active (b) samplers in the second on-field trial.

\subsection{Discussion}

The results show that the scenarios considered in this case are considerably different from the controlled conditions created in the laboratory. In this case, just qualitative plots have been compared, because conversion factors for wood dust were not available. In fact, the conversion factors estimated from laboratory trials in section 3.2 are valid for salts. However, the qualitative comparison presented in this paper is good enough to support preliminary comments.

The first objective of this on-field experiments was to check whether the prototypical sensors could act as good environmental dust sensors. From the comparisons depicted in Fig. 9, it can be noticed that there is no correlation between the measurements of the two sensors and the one of the benchmark. There is a high likelihood that the different plots are due to the low dust concentration at such a distance from the source. That concentration was sensed by the benchmark but not by the sensors. Another possible reason is that after migration from its source, dust spread unevenly around the room, so the sensed values are markedly different. But the first circumstance looks more reasonable.

Once the sensors have been approached to the source, the passive sensor gives back quite reliable results, and the peak detected by the benchmark is present also in the plot of the passive sensors (Fig. 10). Oddly enough, the active sensor, which gave back good results under controlled conditions, did not work well in this case. This could be due to the way such sensor is driven to take measurements, which was described in sub-section 2.2.1. Firstly, it is turned on for 30s between two sets of measurements. Secondly, each measurements takes $60 \mathrm{~s}$, because it is weighed over a certain air flow rate, which is moved by a heater. So this policy could have hampered the possibility to detect sudden dust concentration rise, such as the one detected 
by the passive sensors, which was instead programmed to collect one record every $10 \mathrm{~s}$. As a consequence, further tests must be done, in order to check whether this phenomenon is recurrent and whether there is room for improvement, e.g. reducing measurement time lags.

\section{Conclusions}

Our comparison between the passive sampler and the active sampler showed that both are able to sense the particulate matter typically found in work places like construction sites. To that end, we assembled and tested an untethered monitoring setup, made of wireless devices based on the Zigbee ${ }^{\mathrm{TM}}$ communication protocol and mounting two types of dust sensors: one Sharp dust monitoring sensor and one Shinyei dust monitoring sensor.

Such a platform was set up because it would allow pervasive monitoring of mobile sources of dust. In fact, this is not possible through the use of current technologies which are mainly devoted to point measurements and dust sampling. For this reason, this new setup might be considered as a complementary system to some more accurate measurement approaches which are currently used, and it was specifically designed to solve the particular challenges posed by construction sites.

The experimental results showed that the reliability of the two sensors is strictly related to the context they are working in. In particular, the active sampler performed better when working under controlled conditions in the machine laboratory. But it was not responsive enough to detect peaks when immersed in a real work place. On the other hand, the passive sampler was more responsive, but less accurate when tested under controlled conditions. So our opinion is that more tests must be performed in real work places, in order to check further the behaviour of the two sensors. Also, a deeper analysis on the possibility to reduce the time for stabilization required by the active sensor should be performed. In fact, its scarce responsiveness might be determined by the long time required to get one record, which could flatten peaks. Additional considerations should be done in terms of cumulative readings over longer time windows.

\section{Acknowledgments}

The authors wish to express their gratitude to Eng. Massimo Monti and Mr. Roberto Mancini, who kindly supported the tests and analyses presented in this paper.

\section{References}

[1] Kukadia V., Upton S., Hall D. Control of dust from construction and demolition activities. BRE
Bookshop eds., 2003. ISBN: 1860816126.

[2] WHO 2006 - The World Health Organization. Air quality guidelines - Global Update 2005. Printed in Germany by Druckpartner Moser.

[3] Environmental Act Part IV. 1995. The Stationary Office Ltd. ISBN: 0105425958.

[4] Watson J.G., Chow J.C., DuBois D., Green M., Frank N., Pitchford M. Guidance for network design and optimum site exposure for PM2.5 and PM10. Research Triangle Park, NC: U.S. Environmental Protection Agency (E.P.A.), Office of Air Quality Planning and Standards. 1997.

[5] Flanagan M. E., Seixas N., Majar M., Camp J., Morgan M. Silica dust exposure during selected construction activities. AIHA Journal 64: 319-328, 2003.

[6] Sukys R., Cyras P. and Sakenaite J. Economical loss due to non-compliance with requirements for personnel safety and health in Lithuanian construction sector, Journal of Civil Engineering and Management 17(2): 168-176, 2011.

[7] Naticchia B., Vaccarini M., Carbonari A. A monitoring system for real-time interference control on large construction sites. Automation in Construction 29:148-160, 2013.

[8] Budde M., Busse M., Beigl M. Investigating the use of commodity dust sensors for the embedded measurement of particulate matter. In Proceedings of 9th International Conference on Networked Sensing Systems (INSS), Antwerp, Belgium, June 2012.

[9] Lang R.J. Capillary Wave Theory in Ultrasonic Field. J. Acoust. Soc. Am., 34(6), 1962. 